\title{
sciendo
}

DOI 10.2478/sbe-2020-0020

SBE no. 15(1) 2020

\section{AN ALTERNATIVE VIEW TO THE GLOBAL COAL TRADE: COMPLEX NETWORK APPROACH}

\author{
SOYYIGIT SEMANUR \\ Erzincan Binali Yıldırım University, Turkey \\ TOPUZ HÜSEYIN \\ Akdeniz University, Turkey \\ ÖZEKICiOĞLU HALİL \\ Akdeniz University, Turkey
}

\begin{abstract}
:
The role of energy for the developmental process of nations is a known fact due to being crucial input for any phase of production of goods and services. That's the reason why countries that are rich in energy resources also have strategic power in terms of the international trade of these resources. On the other hand, it becomes important to provide energy security for countries that are resource-poor. Although green energy has become preferred one, fossil fuel energy keeps its place as one of the most used energy resources. That's why in this study it is aimed to determine the major providers and users of coal as a type of fossil fuel energy resources. It is vital to investigate the structure of global coal trade structure to determine the weaknesses and strength of supply and use of coal. Network approach provides a holistic view to the system analyzed and presents more realistic (high-degree) indicators to analyze it. In this study, global trade network of coal is analyzed from 2000 to 2017 via network analysis. Changing structure and evolution of global coal trade has been revealed via some topological parameters which are specific to complex networks such as density, clustering, assortativity/disassortativity, centrality and degree distribution.
\end{abstract}

Key words: Energy resources, International trade, Network analysis, Coal trade

\section{Introduction}

Energy as a key factor for countries to provide economic growth has a crucial role. Depending on the consumption level of fossil energy, it can be said that this energy resource maintains its importance despite the growing importance of green energy resources. In a study, Jin and Kim (2018) analyzed the relationship between coal consumption and economic growth for 30 OECD countries and 32 non-OECD countries for the 1990-2013 period. The authors found a negative long-run relationship between these two variables for non-OECD countries while there is a positive short-run relationship. Li 
and Li (2011) analyzed the relationship between coal consumption and economic growth for China and India from 1965 to 2006. They found a unidirectional causal relation from coal consumption to GDP in India. In another study in which Shahbaz and Dube (2012) analyzed the relationship between coal consumption and economic growth, the authors found a positive impact of coal consumption on economic growth in Pakistan over the period 1972-2009.

However, uneven distribution of natural energy resources among countries makes these resources become more strategically important for countries. Countries which are rich in energy resources have strategic power as energy providers to the world and these countries become crucial for energy security of the world due to supply shocks. On the other hand, countries that are importers of energy resources have an important role in terms of demand-side and they are also potential source of demand shocks. Any shock either in supply or in demand of energy resources may cause spillover effects due to crucial roles of these resources in production process since all countries around the world have become connected to each other with increasing globalization. That's the reason why it matters to investigate the trade relations among the providers and the users of energy resources with high-degree indicators.

On this purpose, this paper focuses on complex network approach to international trade of coal for 2000-2017 period. The main objectives in using network tools are: (i) to determine complex structure of this trade network, (ii) to calculate complex system measures such as density, assortativity/disassortativity, clustering and centrality, (iii) to compare the centrality measures (hub and authority centrality) as high-degree indicators with import/export shares of countries which are first-degree indicators, (iv) to reveal the differences between the first-degree and second-degree indicators, $(v)$ to evaluate the evolution of these high-degree statistics and the whole picture obtained. Especially, determination of the major providers and users of coal depending on hub and authority centralities has importance to detect the most strategically important and the most fragile countries in this network.

Following these purposes, outline of the study is as follows: Trend of world energy consumption is searched in Section 2 in order to show the importance of coal. Literature review is summarized in the Section 3 . Some methodological information is given and the data are introduced in the Section 4. The findings of the study is presented in the Section 5. And finally the results are evaluated in the Section 6.

\section{World energy consumption}

Coal, as a type of fossil fuel energy, has a declining consumption trend all over the world recently since the rising awareness about possible environmental and health problems caused by fossil fuel energy use. Countries announce some measures to decrease the usage of non-renewable energy and some preparations to start using renewable energy. Even China which is the biggest coal consumer around the world announced a plan to decline the share of coal consumption in total energy consumption below \% 58 by 2020 and took concrete steps via 13 th Five-Year Plan on this purpose (China Coal Consumption Cap Plan and Research Report, 2015). 
However, fossil energy consumption around the world has still the highest share in total consumption. It can be observed in Graph 1 that coal consumption ranks as second following oil consumption. Natural gas which is another type of fossil fuel is the third most commonly used type of energy around the world. Graph 1 reveals the continuing importance of fossil energy use in spite of the environmental awareness.

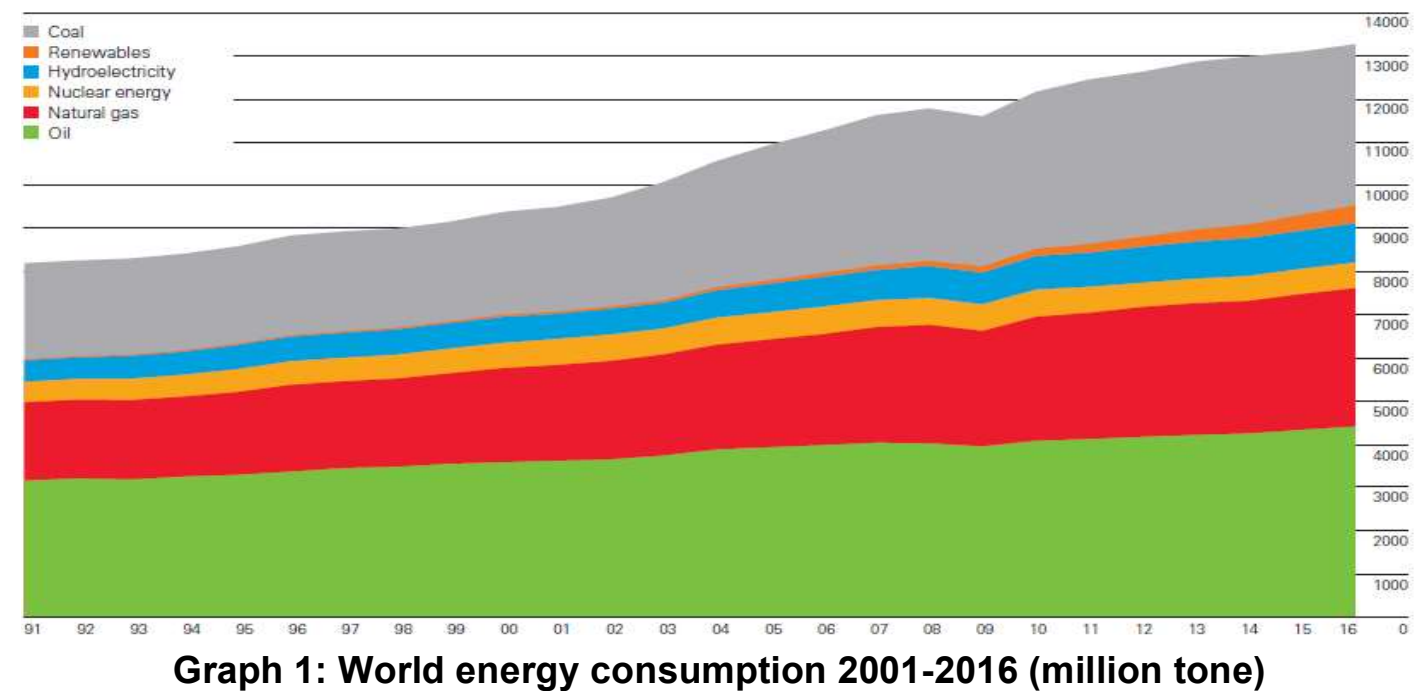

Source: BP Statistical Review of World Energy, 2017

Looking at the regional consumption of energy around the world is also informative about the importance of fossil fuel and coal. As is seen in Graph 2, coal has the highest share in terms of consumption in Asia-Pacific which involve the most important economies of the world in terms of real production such as China, India, Malaysia, Thailand, South Korea, Singapore, Vietnam etc.

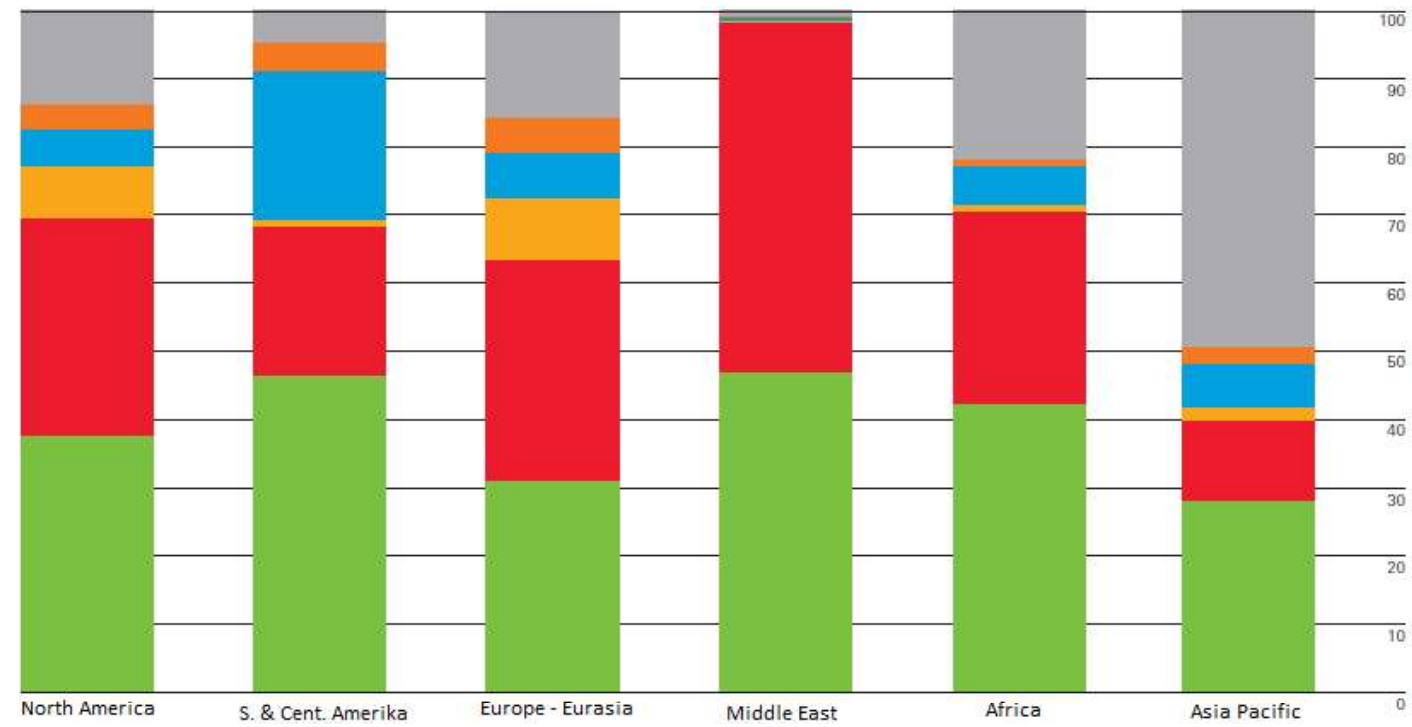

Graph 2: Regional consumption by fuel 2016

Source: BP Statistical Review of World Energy, 2017 
These graphs indicate that fossil fuel consumption in general and coal consumption in specific will continue being one of the major energy types in future. That's why it is necessary to determine the major importers and exporters in global market of this energy source.

However, Fagiolo et al. (2013) argue that standard approaches to international trade make analysis in terms of some country specific indicators which are also named first-degree indicators. However, network analysis moves a step further and takes also indirect trade relationships between partners into consideration. That's why the statistics obtained by network tools are called 'high-degree indicators' such as centrality, connectedness, assortativity/disassortativity, power-law degree distribution etc.

Duenas and Fagiolo (2011) specify that topological analysis of international trade has importance due to two reasons: (i) contagion of crisis and transmission of shocks can be understood only by analyzing this structure with a holistic approach and, (ii) the effect of the positions of countries in this network structure is determinant of these countries future growth.

\section{Literature review}

International trade of energy has recently become a popular subject to analyze as a complex network. In the literature, there is a vast number of analyses on international trade of energy via network tools.

In one of these studies, De Benedictis et al. (2013) analyzed international trade network of different products including crude oil. Their findings revealed that Russia had a central role in the European system and Kazakhstan had a role as a secondary hub in Central Asia bridging between Europe and China.

Du et al. (2016) analyzed the topological properties of the world crude oil network. Their findings supported the fitness to power-law distribution. The authors also found that the crude oil trade network has a disassortative structure.

Zhang et al. (2018) studied the global pattern of international trade of crude oil and petroleum products. Their findings showed the impact of the global crisis on the global trade of crude oil and petroleum products. They also revealed that geographical position of countries is more essential for the trade of crude oil than the trade of petroleum products. Another result of their study is that connectivity measure is higher for petroleum products network than the crude oil network.

Crude oil is not the only energy resource that is analyzed with network tools. There are also some other studies focusing on network structure of natural gas and coal trade. In one of these studies, Geng et al. (2014) analyzed liquid and pipeline gas trade network. Their findings indicated that both of the networks display scale-free distribution. In this structure, the countries in the liquid natural gas trade networks were linked more closely than the countries in the pipeline gas trade network.

Chen et al. (2016) examined the trade competition pattern of global liquefied natural gas trade via network analysis from 2005 to 2014. The authors studied the main exporter group in this network and the evolution of it. Besides, the authors measured the competitiveness of the liquefied natural gas exporters. 
Zhong et al. (2017) analyzed emergy of fossil fuel. The authors first transformed the trade quantity of fossil fuels (coal, crude oil and natural gas) into emergy and then summed of these three emergies. The authors analyzed the role of countries in this global trade network by using top relationships, central positions and the roles of the countries in trade groups.

In another study, Xu and Qin (2015) analyzed world coal trade network consist of 212 countries from 2001 to 2010 . Their findings showed that the size of the network was stable during the period while the links and trade volume grew overtime. They also revealed the heterogeneous structure of the network depending on the uneven distribution. The authors also proved the core-periphery structure of the network and stability of the core layers.

As is seen in the literature review, there is not much study on international coal trade via network tools in contrast to other types of the fossil fuel namely crude oil and natural gas. In this study, it is aimed to analyze international coal trade in terms of complex network structures. After revealing the topological properties and investigating the evolution of these properties of the network, hub and authority centrality measures for each country is calculated. There is also comparison of these high-degree indicators with the first-degree indicators of standard measures.

\section{Methodology and data}

Complex system is defined as a system in which there exist interacting parts and these interactions among them constitute completely different properties from the properties of the parts (Tesfatsion, 2006: 836). According to Reichardt (2009), decomposition of the system into its parts is the first step to understand a complex system. Recihardt (2009) also states that network is an appropriate tool to represent and analyze complex systems.

A network is simply defined as a set that composes of nodes and links connecting these nodes (Newman: 2). Network theory has arisen out of graph theory that is subbranch of mathematics in which networks correspond to graphs. A simple network is presented as $\mathrm{G}=(\mathrm{V}, \mathrm{E})$ in graph theory in which $\mathrm{V}$ represents nodes (vertices) and $\mathrm{E}$ represents links (edges) (Reichardt 2009). There are some classifications on network types related to the properties of links such as binary-weighted or directed-undirected. Binary networks correspond to networks in which all links have equal importance. In case of weighted network, each link has a distinct weight and represents heterogeneity. In undirected networks links do not reflect a casual or a directional relationship while in directed networks links provide information about the direction of the relations between nodes (Chow 2013).

First of all, it is necessary to investigate degree / strength distribution of a network since this distribution provides information about the complexity of the network. Mathematical function of power-law distribution is presented as in Equity (1) (Newman 2010):

$$
P(k)=C k^{-\alpha}
$$


in which $\alpha$ is known as the exponent of the power-law distribution. This exponent is usually in the range of $2 \leq \alpha \leq 3$. Clauset (2011) states that fitness to power-law distribution is an indication of complexity in the generating process of the structure examined. Power-law distribution is known as belonging to the class of fat-tailed distributions which have higher peaks and fat tails in comparison to Poisson distribution. One method to determine existence of fat-tailed distribution is to look at the kurtosis measure. If the kurtosis value is positive, then the distribution follows fat-tail distribution (Decarlo 1997). It is also stated that most real world networks display right-skewed distributions and these distributions approximate power-law distribution (Leon Rincon et al. 2015). Thus, skewness measure gives information about distributional asymmetry and is used to determine which side of a distribution has a fat-tail. If the skewness measure has positive value, then the fat-tail is on the right and the distribution is said to be right-skewed (Von Hippel 2010). However, it is also necessary to prove the fitness to power-law distribution statistically. Kolmogorov-Smirnov test is the other method to determine the distribution.

Basically, there are four extent to analyze a network in terms of its topology: connectivity, assortativity/disassortativity, clustering, and centrality. In node level, connectivity is measured by node degree or node strength depending on the type of the network. Higher node degree/node strength value of node i means that node i has bigger impact over the network (Howell 2012). In network-level, connectivity is measured by density coefficient throughout the network. Density coefficient is an indicator that lays in the range of $0 \leq \rho \leq 1$ and indicates in what ratio the maximum possible count of links exist in the network. In a simple network that does not contain self-loop and multi-link, density coefficient is formulized as in Equation (2) (Newman 2010):

$$
\rho=\frac{m}{n(n-1)}
$$

in which $m$ represents the count of actual links and $n$ represents the count of nodes.

Assortativity / disassortativity is another important property of a network. In a network structure, if nodes which have high degree/strength tend to have link with nodes which have high degree/strength and vice versa, it indicates that nodes have tendency to connect to the similar nodes. This structure is defined as assortative. If nodes with high degree/strength tend to have link with nodes which have low degree/strength and vice versa, this indicates that nodes have tendency to connect to the nodes which are dissimilar. This structure is called disassortative structure. One way to determine which structure exists in a network is to plot degree/strength and ANND/ANNS (average nearest node degree/ strength) values of all nodes (Reichardt 2009).
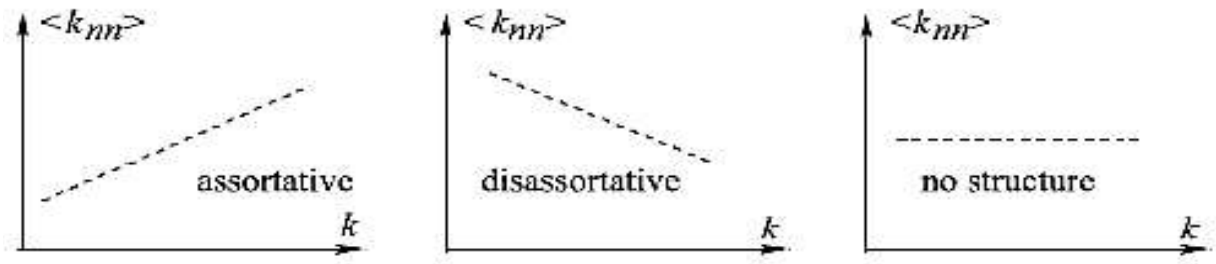

Graph 3. Assortative / disassortative structure

Source: Caldarelli 
In Graph 3, positive correlation between ANND $\left.\left(<k_{n n}\right\rangle\right)$ and degree $(\mathrm{k})$ indicates the existence of assortativity while negative relation indicates the existence of disassortativity (Caldarelli). Disassortativity is an indicator of core-periphery property of a network. That's why detection of disassortative structure in a network have importance (Csermely 2013). The second method to determine assortativity/disassortativity in a network is to calculate a correlation coefficient which is called as assortativity correlation coefficient. It refers to assortativity if the correlation coefficient is positive while it refers to disassortativity if the coefficient is negative (Reichardt 2009).

As another prominent property, clustering refers to the relation between two nodes which are also related to a node in common. Within this scope, it is evaluated as an indicator of transitivity in networks. Clustering in a network is measured by a coefficient both in node-level and in network-level. Clustering coefficient for node $i$ is formulized as follows (Serrano and Boguna 2006):

$$
c_{i}=\frac{T_{i}}{k_{i}\left(k_{i}-1\right)}
$$

in which $T_{i}$ represents the count of triangles that pass over the node $\mathrm{i}$ and $k_{i}$ represents the degree of node i. Clustering coefficient in network-level is obtained by taking average of the clustering coefficient for all nodes in the network. This coefficient is a number that lays in the range of $0 \leq \rho \leq 1$. If the coefficient is equal to 1 , then it is said that there is perfect transitivity among the nodes (Wang and Chen 2003).

There is a lot of measures to determine centrality which is also another crucial property of a network. Centrality of a node refers to significance of a node in the network. Some of the centrality measures such as degree, closeness, betweenness, eigenvector, Katz and PageRank are different measures that use different approaches in calculation. Hub and authority centralities which was developed by Kleinberg (1999) via Hyperlinked Induced Topic Search (HITs) algorithm have become prevalent in complex network analysis recently.

Nodes with a large number of out-degree are named as hubs while nodes with ma large number of in-degree are named as authorities in graph theory. Kleinberg (1999) has revealed the existence of 'mutually reinforcing relationship' between hubs and authorities, It implies that a hub is a good hub if it has a large number of 'good' authorities. Similarly, an authority is a good authority if it has a large number of good hubs. An algorithm (HITs) has been developed by Kleinberg (1999) that calculate a hub score and an authority score to each node on the basis of this mutually reinforcing relationship.

Matrix notation of hub and authority equations describing this mutually reinforcing relationship is written as in Equation (4), respectively (Newman 2010):

$$
x=\alpha A y, \quad y=\beta A^{T} x
$$

One gets Equation (5) by combining the equations in Equation (4):

$$
A A^{T} x=\lambda x, \quad A^{T} A y=\lambda y,
$$


In this statement $\lambda=(\alpha \beta)^{-1}$ is provided. The eigenvectors of $A A^{T}$ and $A^{T} A$ are respectively equal to authority and hub centralities with the same eigenvalue $\lambda$. By multiplying both side of $A A^{T} x=\lambda x$ by $A^{T}$, one gets;

$$
A^{T} A\left(A^{T} x\right)=\lambda\left(A^{T} x\right)
$$

in which it can be seen that $A^{T} x$ is an eigenvector of $A^{T} A$ with the same eigenvalue, $\lambda$. Hence, by comparing with Equation (5), it can be written as Equation (7);

$$
y=A^{T} x
$$

It can be observed in Equation (7) that it is possible to obtain hub centrality vector easily once authority centrality vector is given (Newman 2010).

After using HITs algorithm to get centralities in binary networks, HITs algorithm has been developed for weighted networks. After developing weighted HITs (w-HITs) algorithm, it has become possible to analyze international trade as a heterogeneous network structure and to rank countries according to their import/export impacts taking bilateral relations into consideration (Wei and Liu 2012).

w-HITs algorithm works with an iterative process. In this process, country $u$ is linked with an export property $y^{u}$ and with an import property $x^{u} . y^{u}$ represents the export impact of $u$ on international trade network while $x^{u}$ represents the import impact of country u. Afterwards, $\alpha$ and $\beta$ operations are defined to determine the import impact and export impact of country $u$. Operation a updates the import impact $x^{u}$ and operation $\beta$ updates the export impact $y^{u}$ continually.

$$
\begin{aligned}
x^{u} \leftarrow \sum_{v:(v, u) \epsilon E} w_{v u} y^{v} \\
y^{u} \leftarrow \sum_{v:(u, v) \epsilon E} w_{u v} x^{v}
\end{aligned}
$$

In Equation (8), $w_{v u}$ represents the export volume from country $v$ to country $u$. It can be said that the import value of country $u$ from country $v$ and export property of country $v$ determine the import property of country $u$. In a similar way, export value of country $u$ to country $v$ and the import property of country $v$ determine the export property of country $u$. Progressively, these $x^{u}$ and $y^{u}$ values converge to their equilibrium values at the end of this iterative process (Wei and Liu 2012).

In this study, international coal trade network has been analyzed from 2000 to 2017. The data have been obtained from United Nations COMTRADE database. The data includes bilateral coal trade values based on SITC Rev.3. R Project statistic software has been used for the application.

\section{Results}

Coal is a crucial energy resource all over the world although usage of it is aimed to be confined since excess use of coal is one of the reasons of environmental problems 
such as global warming, air pollution etc. In 2016, world total coal consumption is 3.7 million tons of which 1.9 billion tons is consumed by China. Asia-Pacific has the largest consumption with 2.8 billion tons on regional basis (BP 2017). When the emergent structures of these countries are taken into consideration, the importance of coal supply for global economy can be better understood which means that supplier countries in international coal network have strategic prominence while demander countries are in a risky position due to their dependency on this resource.

However, the claim of this study is the complexity of global coal trade network. That's why determination of complexity in this network is the first step of the study. As explained above, power-law distribution is an indication of underlying complexity in the generating process of this structure. Thus, primary purpose of the study is to determine whether degree distribution follows a power-law or not.

Table 2. Testing fitness to power-law distribution

\begin{tabular}{|c|c|c|c|c|}
\hline Years & Skewness & Kurtosis & $\mathbf{a}$ & p-value \\
\hline 2000 & 6.940 & 60.305 & 1.317 & 0.358 \\
\hline 2001 & 7.061 & 62.197 & 1.175 & 0.192 \\
\hline 2002 & 7.650 & 72.188 & 1.183 & 0.279 \\
\hline 2003 & 6.940 & 59.025 & 1.221 & 0.239 \\
\hline 2004 & 6.672 & 53.153 & 1.314 & 0.282 \\
\hline 2005 & 8.051 & 80.389 & 3.235 & 0.999 \\
\hline 2006 & 8.115 & 82.009 & 3.259 & 0.999 \\
\hline 2007 & 7.129 & 64.531 & 1.446 & 0.766 \\
\hline 2008 & 9.133 & 99.978 & 1.402 & 0.559 \\
\hline 2009 & 8.763 & 90.814 & 2.550 & 0.999 \\
\hline 2010 & 8.274 & 81.557 & 1.416 & 0.631 \\
\hline 2011 & 7.958 & 74.970 & 1.250 & 0.339 \\
\hline 2012 & 7.712 & 69.756 & 1.265 & 0.299 \\
\hline 2013 & 7.849 & 71.609 & 1.342 & 0.477 \\
\hline 2014 & 10.803 & 130.067 & 1.505 & 0.744 \\
\hline 2015 & 8.674 & 85.750 & 1.192 & 0.037 \\
\hline 2016 & 8.982 & 92.545 & 1.179 & 0.103 \\
\hline 2017 & 9.064 & 94.604 & 1.442 & 0.927 \\
\hline
\end{tabular}

Source: Author's calculation.

As explained, investigation of skewness and kurtosis measures is one way to search fitness to power-law degree distribution in a network. Positive skewness and kurtosis values implies that there is a right-skewed distribution. However, it is also necessary to prove the power-law distribution statistically in network analysis. KolmogorovSmirnov test is the other way of investigation of power-law. According to the results which are shown in Table 2, positive values of skewness and kurtosis give an idea about fitness to power-law degree distribution. Kolmogorov-Smirnov test results also support this result except the year 2015 in which p-value is lower than 0.05 meaning that the test rejected the hypothesis that the original data could have been drawn from the fitted power-law distribution. Power-law distribution indicates the heterogeneity of connectedness of the countries meaning that there is a small number of countries with high export volume and 


\section{Studies in Business and Economics no. 15(1)/2020}

there is a great number of countries with low export volume. This result proves the complexity of global coal trade network.

Before evaluating the findings of the analysis in terms of a complex network, some information about the count of nodes and links per annum can be seen in Table 3. Count of nodes represent the countries that are trade partners as exporter or importer. It can be said that there is an observable increase in count of either nodes or links during the period.

Table 3. Count of nodes and links

\begin{tabular}{|c|c|c|c|c|c|}
\hline Years & Nodes & Links & Years & Nodes & Links \\
\hline 2000 & 165 & 1327 & 2009 & 170 & 1893 \\
\hline 2001 & 171 & 1458 & 2010 & 170 & 2002 \\
\hline 2002 & 174 & 1550 & 2011 & 181 & 2026 \\
\hline 2003 & 168 & 1533 & 2012 & 180 & 2033 \\
\hline 2004 & 176 & 1704 & 2013 & 179 & 2097 \\
\hline 2005 & 172 & 1787 & 2014 & 179 & 1904 \\
\hline 2006 & 176 & 1859 & 2015 & 180 & 1957 \\
\hline 2007 & 173 & 1936 & 2016 & 179 & 2017 \\
\hline 2008 & 175 & 1933 & 2017 & 184 & 1897 \\
\hline
\end{tabular}

Source: Author's calculation

Density coefficient as a connectivity measure is more informative about the real evolution of network structure. When we look at the trend of this measure in Graph 4, it is seen that there is an observable increase till 2010. Thereafter, there is a downward slope accompanied by fluctuation. However, it can be evaluated as a general increase over the period since density coefficient rises from 0.05 in 2000 to 0.06 in 2017.

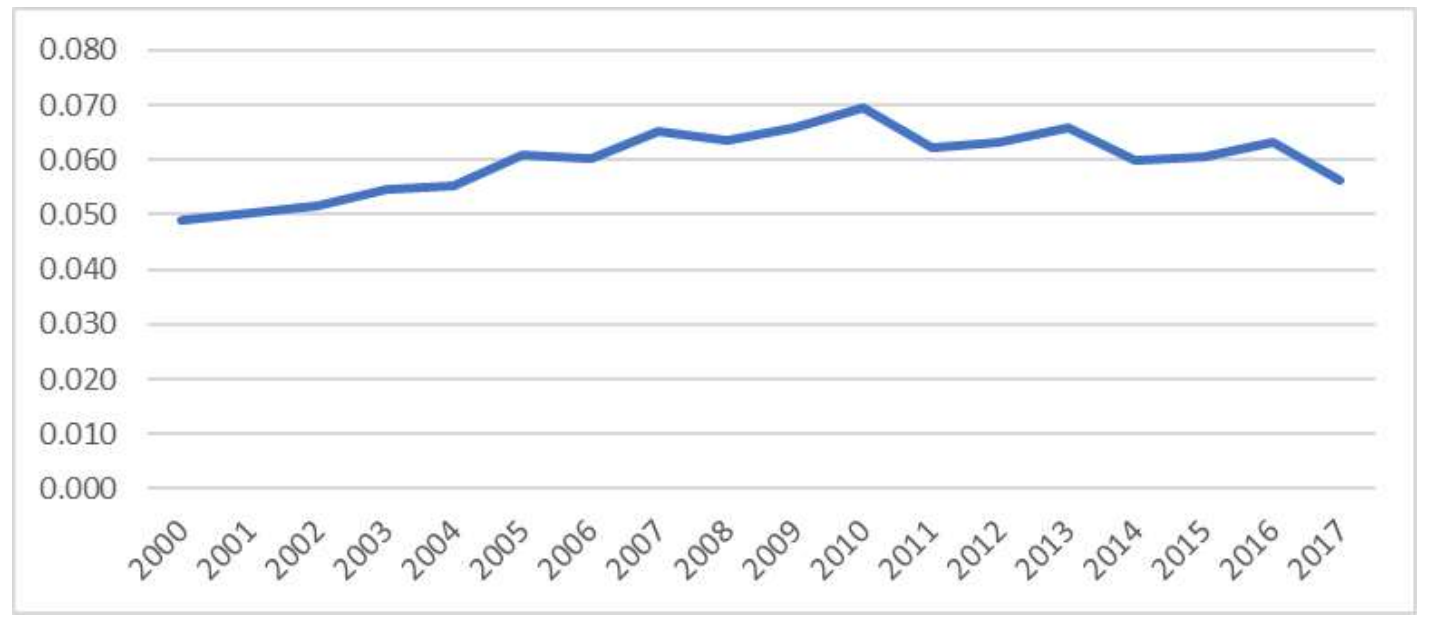

Graph 4. Density coefficient

Source: Author's calculation

Clustering coefficient is another measure related to complex networks meaning that in what ratio neighbors of a node are connected. It is seen that clustering coefficient varies between 0.75 and 0.80 during the period. Clustering coefficient as an indicator of transitivity displays a stable view. 
Table 4. Clustering coefficient

\begin{tabular}{|c|c|c|c|}
\hline Years & Clustering & Years & Clustering \\
\hline 2000 & 0.757 & 2009 & 0.804 \\
\hline 2001 & 0.764 & 2010 & 0.763 \\
\hline 2002 & 0.781 & 2011 & 0.765 \\
\hline 2003 & 0.788 & 2012 & 0.799 \\
\hline 2004 & 0.772 & 2013 & 0.784 \\
\hline 2005 & 0.762 & 2014 & 0.768 \\
\hline 2006 & 0.788 & 2015 & 0.744 \\
\hline 2007 & 0.774 & 2016 & 0.754 \\
\hline 2008 & 0.775 & 2017 & 0.758 \\
\hline
\end{tabular}

Source: Author's calculation.

As mentioned above, assortative or disassortative structure gives an idea about core-periphery structure in complex networks. Assortativity correlation coefficient as a measure to detect of which structure exists in the network is presented in the Tablo 5. It is seen that there is a disassortative structure during the period except the years 2012 and 2015 meaning that there is a core-periphery structure in the international coal trade network except these years since the coefficients are negative. However, it can be said that there is not a perfect disassortativity. Core-periphery structure implies that there are some hub countries in the global coal trade network and there is a periphery consisting of weak trade partners.

Table 5. Assortativity correlation coefficient

\begin{tabular}{|c|c|c|c|}
\hline Years & Assortativity & Years & Assortativity \\
\hline 2000 & -0.015 & 2009 & -0.006 \\
\hline 2001 & -0.034 & 2010 & -0.012 \\
\hline 2002 & -0.025 & 2011 & -0.015 \\
\hline 2003 & -0.011 & 2012 & 0.000 \\
\hline 2004 & -0.033 & 2013 & -0.020 \\
\hline 2005 & -0.011 & 2014 & -0.009 \\
\hline 2006 & -0.027 & 2015 & 0.001 \\
\hline 2007 & -0.024 & 2016 & -0.005 \\
\hline 2008 & -0.017 & 2017 & -0.010 \\
\hline
\end{tabular}

Source: Author's calculation.

After detecting core-periphery structure in a network, it becomes important to determine which countries are in the core and which countries are in the periphery. Centrality measure enables one to determine these countries. As mentioned above, there are several centrality measures. However, hub and authority centralities developed by Kleinberg (1999) are used in this study since the algorithm on which they are based captures the second-order adjacencies of the countries. Before examining the centrality results, it is necessary to express that hub centrality refers to export impact of a country while authority centrality refers to import impact. Export impact of a country, as a highdegree indicator, reflects better result since it also takes into consideration the indirect connections of this country. Import impact of a country also reflects better result since it takes into consideration the indirect connections of the country. After this explanation, 
comparison of import shares of countries with authority centralities and export shares of countries with hub centralities is presented below.

Comparison of country rankings according to export shares and hub centralities (export impacts) is given for 2000 and 2017 in Table 6. Firstly, it is seen that Australia ranks as first in terms of both export share and export impact in 2000. However, country rankings differ from each other for the rest of the list. For example; the US ranks as second in terms of export share in 2000 while ranking as sixth in terms of export impact. China ranks as third in terms of export share while ranking as second in terms of export impact. Indonesia, Colombia, Canada and Russia also have greater impact in global coal trade network as a provider/supplier in terms of export impact when compared to export shares. However, South Africa, Poland and Germany have lower impact in this network as a provider in terms of export impact when compared to export shares.

In 2017, Australia still remains being greatest supplier of coal to the global market according to both export share and export impact. Ranking of these two indicator is similar for second and third countries. However, they differ from each other after that. For example; Colombia ranks as fourth according to export share while it ranks as seventh according to export impact which means that Colombia has a lower impact on this global market as a provider when its connections is taken into consideration even though its export share is high. The same comment can be made for Poland and the Netherlands. However, rankings of Canada, China and Mozambique is greater according to export impacts which means that these countries become more important providers when their connections are evaluated in the system as a whole.

It is also possible to compare hub centralities of both year and to see the evolution. Accordingly, China has an observable declining impact as a provider since it ranks as sixth in 2017 while it ranks as second in 2000. The US and Vietnam also have a declining impact as a provider of this product. However, Russia, South Africa and Indonesia have increasing impact over the period.

Table 6: Comparison of first-degree and high-degree indicators for global coal trade

\begin{tabular}{|c|c|c|c|c|c|c|c|}
\hline \multicolumn{4}{|c|}{2000} & \multicolumn{4}{|c|}{2017} \\
\hline \multicolumn{2}{|c|}{$\begin{array}{c}\text { Export Shares } \\
(\%)\end{array}$} & \multicolumn{2}{|c|}{$\begin{array}{l}\text { Export Impacts } \\
\text { (Hub centralities) }\end{array}$} & \multicolumn{2}{|c|}{$\begin{array}{c}\text { Export Shares } \\
(\%)\end{array}$} & \multicolumn{2}{|c|}{$\begin{array}{l}\text { Export Impacts } \\
\text { (Hub centralities) }\end{array}$} \\
\hline AUS & 0.28 & AUS & 0.92 & AUS & 0.39 & AUS & 0.91 \\
\hline USA & 0.12 & CHN & 0.29 & IDN & 0.19 & IDN & 0.37 \\
\hline $\mathrm{CHN}$ & 0.12 & CAN & 0.20 & RUS & 0.13 & RUS & 0.15 \\
\hline CAN & 0.08 & IDN & 0.13 & $\mathrm{COL}$ & 0.07 & CAN & 0.09 \\
\hline $\mathrm{ZAF}$ & 0.07 & RUS & 0.11 & ZAF & 0.05 & ZAF & 0.06 \\
\hline RUS & 0.07 & USA & 0.08 & CAN & 0.05 & $\mathrm{CHN}$ & 0.04 \\
\hline IDN & 0.06 & ZAF & 0.04 & $\mathrm{CHN}$ & 0.03 & MOZ & 0.03 \\
\hline POL & 0.06 & $\mathrm{COL}$ & 0.01 & POL & 0.03 & $\mathrm{COL}$ & 0.02 \\
\hline $\mathrm{COL}$ & 0.05 & VNM & 0.01 & $\mathrm{MOZ}$ & 0.02 & POL & 0.00 \\
\hline DEU & 0.01 & NZL & 0.01 & NLD & 0.01 & JPN & 0.00 \\
\hline \multicolumn{2}{|c|}{$\begin{array}{c}\text { Import Shares } \\
(\%)\end{array}$} & \multicolumn{2}{|c|}{$\begin{array}{c}\text { Import Impacts } \\
\text { (Authority Centralities) }\end{array}$} & \multicolumn{2}{|c|}{$\begin{array}{c}\text { Import Shares } \\
(\%)\end{array}$} & \multicolumn{2}{|c|}{$\begin{array}{c}\text { Import Impacts } \\
\text { (Authority Centralities) }\end{array}$} \\
\hline JPN & 0.26 & JPN & 0.94 & JPN & 0.18 & JPN & 0.65 \\
\hline KOR & 0.09 & KOR & 0.25 & IND & 0.17 & $\mathrm{CHN}$ & 0.53 \\
\hline DEU & 0.09 & 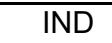 & 0.16 & $\mathrm{CHN}$ & 0.16 & IND & 0.43 \\
\hline
\end{tabular}




\section{Studies in Business and Economics no. 15(1)/2020}

\begin{tabular}{|c|l|l|l|l|l|l|l|}
\hline IND & 0.05 & GBR & 0.08 & KOR & 0.11 & KOR & 0.31 \\
\hline USA & 0.05 & BRA & 0.07 & NLD & 0.03 & NLD & 0.07 \\
\hline NLD & 0.04 & NLD & 0.06 & TUR & 0.03 & MYS & 0.05 \\
\hline GBR & 0.04 & FRA & 0.06 & DEU & 0.02 & BRA & 0.05 \\
\hline FRA & 0.04 & ESP & 0.04 & MYS & 0.02 & VNM & 0.03 \\
\hline CAN & 0.04 & ITA & 0.04 & BRA & 0.02 & PHL & 0.03 \\
\hline ITA & 0.03 & DEU & 0.04 & UKR & 0.02 & THA & 0.03 \\
\hline
\end{tabular}

Source: Author's calculation.

In the sub-section of the Table 6 , there are country rankings according to import shares and import impacts for 2000 and 2017. In 2000, Japan and Korea rank as first and second respectively in terms of both indicators. However, Germany ranks as tenth according to import impact while ranking as third according to import share meaning that Germany has lower impact on global coal market as a user when the system is evaluated as a whole and indirect adjacencies are taken into consideration. In 2000 , India ranks as third in terms of import impact. The UK also ranks higher according to import impact when compared to import share. Brazil is the sixth country as coal user in terms of import impact even though it does not rank among the top ten countries in terms of import shares.

In 2017, Japan ranks as first in terms of the both indicators. However, China ranks as second in terms of import impact while it ranks as third in terms of import share. It means that this country is the second major user of coal following Japan in global market. It is notable that the top ten countries in 2017 mostly consist of Asian countries while top ten countries include mainly include European countries in 2000. Thus, import impact reflects the evolution of the demand-side of the global coal market over the period.

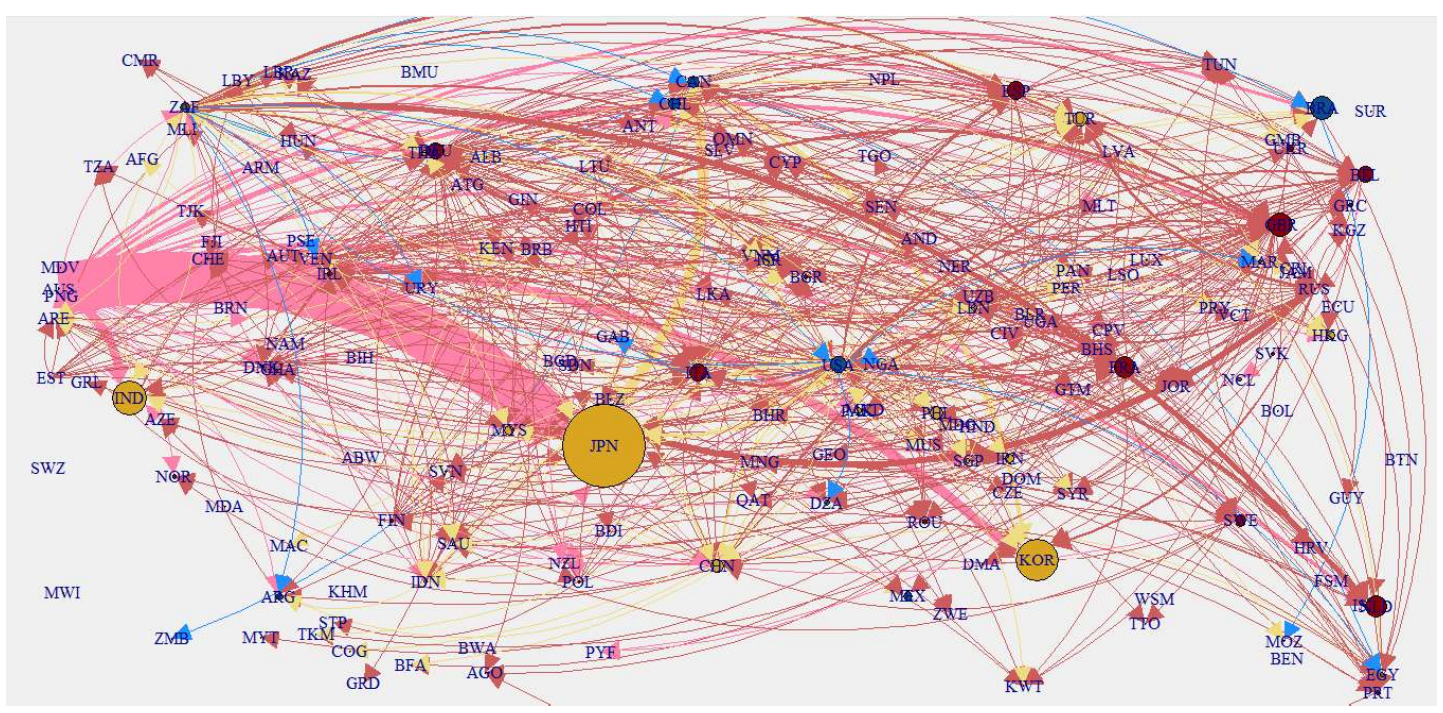

(a) 2000 


\section{Studies in Business and Economics no. 15(1)/2020}

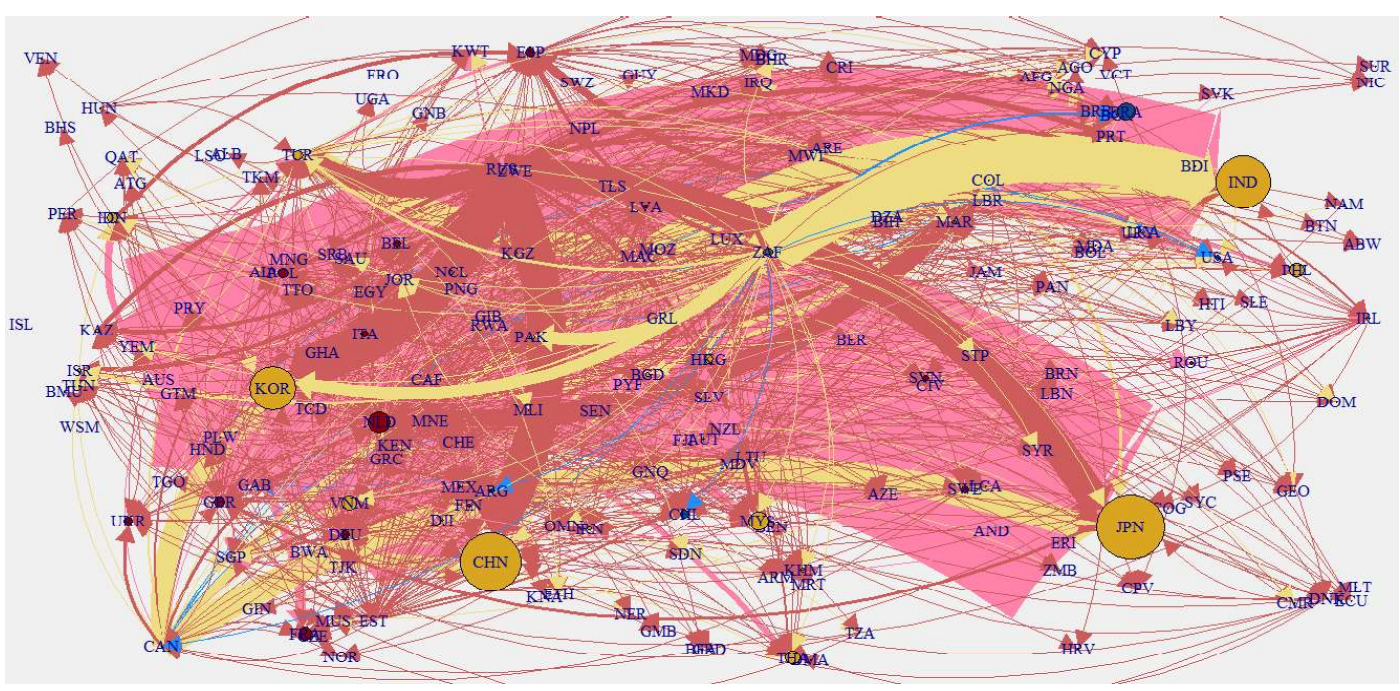

(b) 2017

Figure 1: Visualization of international coal trade network regarding to import impacts (authority centralities)

One of the advantages of network analysis is to enable one to see the whole picture as per above in Figure 1. There are visualizations of international coal trade network for 2000 and 2017 in Figure 1. The visualizations (a) and (b) in Figure 1 summarize the explanations related to sub-section of Table 6 . In these visualizations, countries have been grouped based on the continent that they belong to and each color represents a distinct continent. The size of each node (country) is proportional to is authority centrality measure. The rising importance of Asian countries from 2000 to 2017 can be observed in Figure 1.

After evaluating the network-level statistics in terms of network topology, nodelevel evaluation may be more informative to reflect the evolution through the period. That's why centrality measures are investigated below in terms of important countries as provider and user.
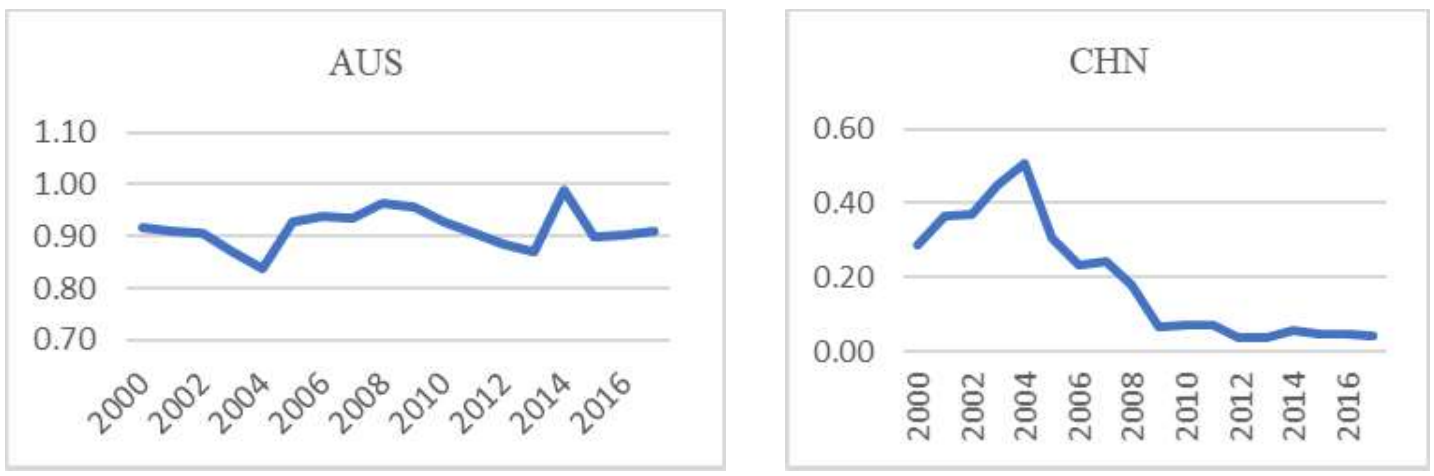
Studies in Business and Economics no. 15(1)/2020
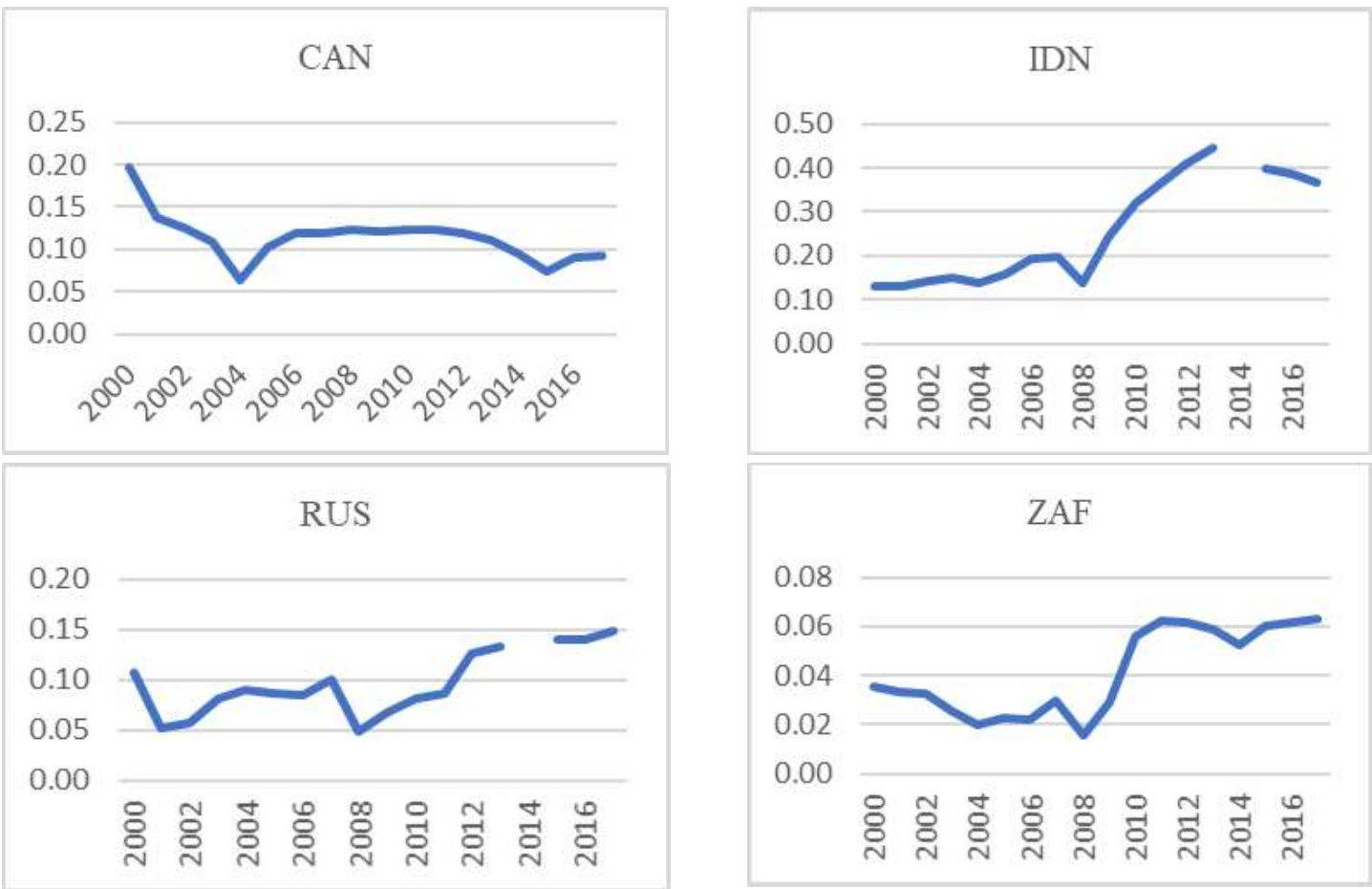

Graph 5. Hub centralities of major countries as coal providers

In Graph 5, it is seen that Australia has the highest hub centrality values. Downward trend of China's hub centrality is conspicuous. It falls from 0.29 in 2000 to 0.04 in 2016. Japan also has decreasing values from 0.94 in 2000 to 0.65 in 2016 . Indonesia has the highest increase of hub centrality although Russia, South Africa and Korea also have increasing export impacts.

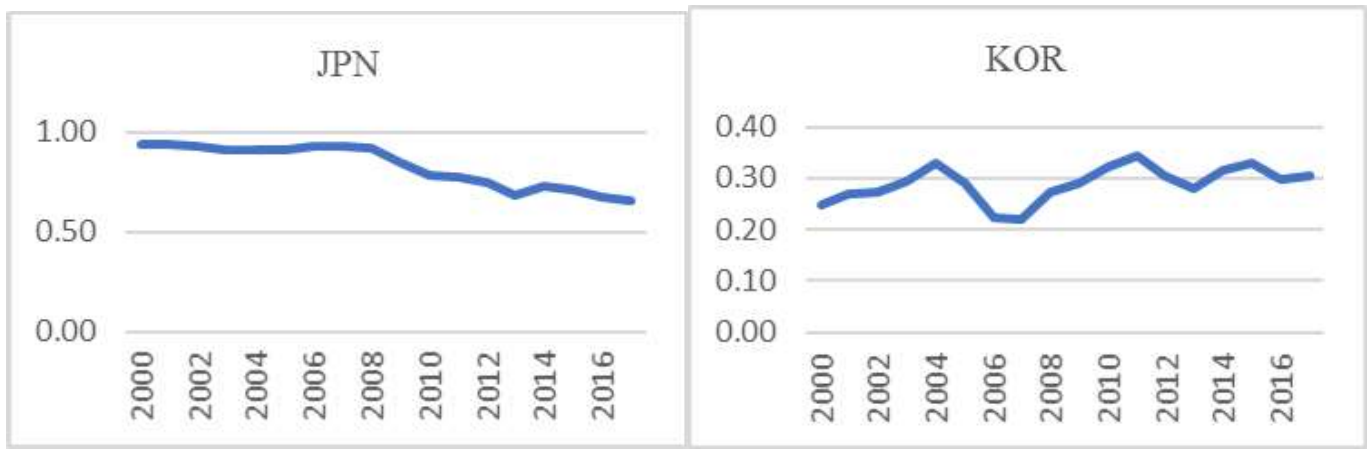




\section{Studies in Business and Economics no. 15(1)/2020}
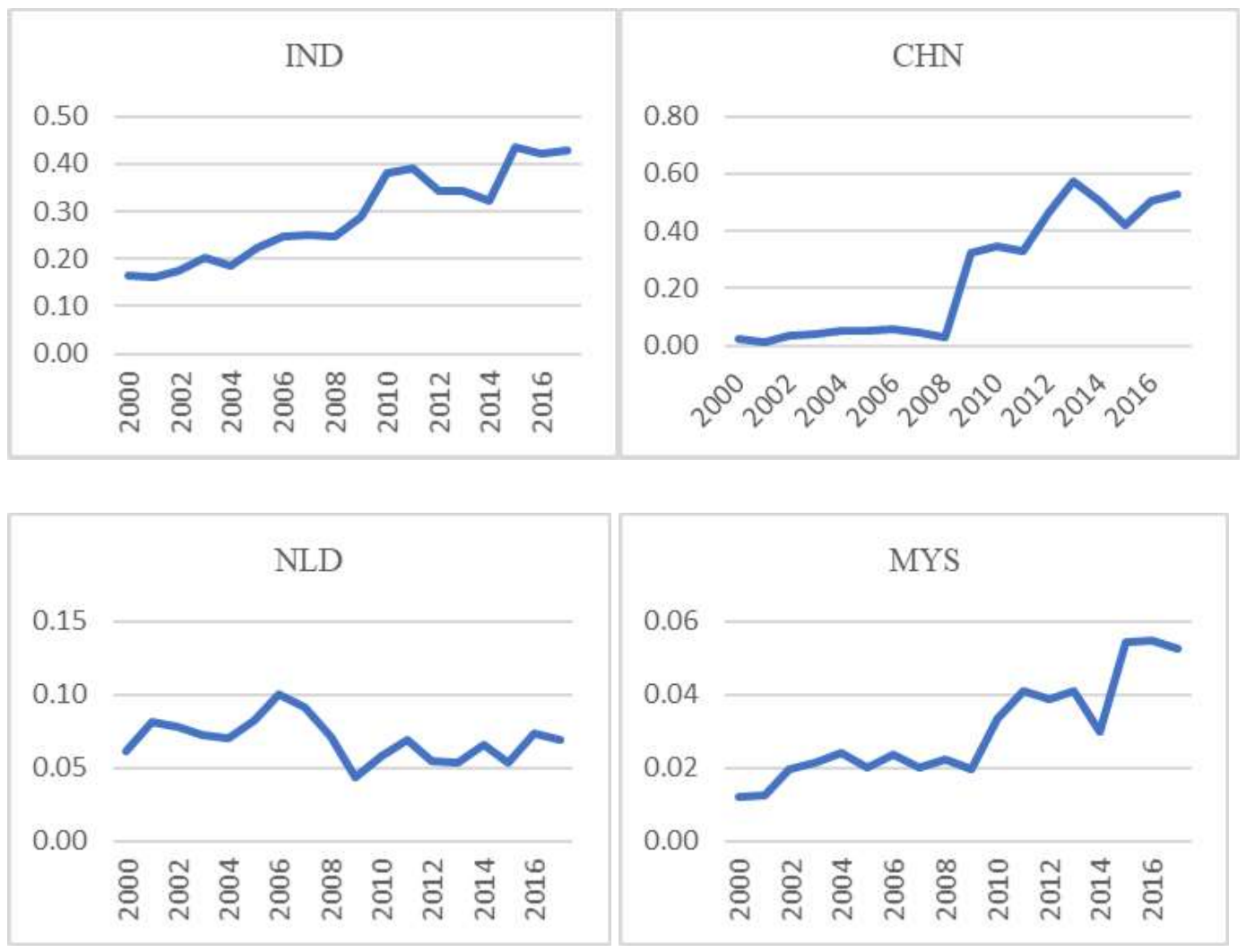

Graph 6: Authority centralities of major countries as coal users

It is seen in Graph 6 that China has the highest import impact which rises from 0.02 in 2000 to 0.53 in 2016. India, Korea and Malaysia also have rising import impact values. However, Japan has an increasing trend of import impact through the period.

\section{Discussion}

Energy is an irreplaceable input of production process for all economies. There is a current awareness of some problems such as climate change, natural disasters, loss of species, health problems caused by use of fossil fuel energy recently. This awareness has brought green energy into the forefront and countries has started taking measures and extending the use of renewable energy.

However, fossil fuel is still the most major source in total energy consumption of the world. On regional basis, it is mostly consumed in Asia-Pacific region which include emerging countries which need more energy resources to maintain their productiveness. It means that fossil fuel energy consumption will maintain its importance in the future.

Coal ranks as second in terms of consumption following crude oil. Thus, it is also important to investigate global coal trade due to uneven distribution of energy resources. Finding of the analysis that represents the fitness to power-law distribution indicates that global coal trade network has complex structure. It implies that there is a heterogeneous structure in terms of connectedness in the network. In terms of connectivity in networklevel, there is an increasing trend overall although connectivity has started declining since 
2010. Global coal trade network also exhibits core-periphery structure meaning that there is a few hub (central exporter) countries and a lot of periphery countries. Centrality measures are observed to put different results from the import/export shares. Thus, it is more reliable to evaluate the network based on these high-degree statistics since these statistics take second-order adjacencies into consideration. When the evolution of the importer countries is investigated with a holistic view, it is seen that Asian countries have become more important users of this energy resource according to high-degree indicators when compared to import shares which is a first-degree indicator.

These results support the results found by Xu and Qin (2015). A further step of this analysis may be to simulate impacts of a probable supply-shock or demand-shock of energy with reference to different scenarios.

\section{References}

An H, Zhong W, Chen Y, Li H, Gao X (2014) Features and evolution of international crude oil trade relationship: a trading-based network analysis. Energy. https://doi.org/10.1016/j.energy.2014.06.095

BP (2017) BP Statistical Review of World Energy. $66^{\text {th }}$ edition.

BP (2017) BP Statistical Review of World Energy: Coal. $66^{\text {th }}$ edition.

Caldarelli G. Introduction to Graph Theory. http://www.guidocaldarelli.com/images/lectures/2018/Lecture-01.pdf. Accessed 10 September 2018.

Chen Z, An H, Gao X, Li H, Hao X (2016) Competition Pattern of the Global Liquefied Natural Gas (LNG) Trade by Network Analysis. Journal of Natural Gas Science and Engineering. https://doi.org/10.1016/j.jngse.2016.06.022

Cheng S, Song L, Li X (2014) Evolution of spatial pattern of crude oil trade. Studies in Sociology of Science. DOI:10.3968/j.sss.1923018420140501.3995

Chow W (2013) An Anatomy of the World Trade Network. http://www.hkeconomy.gov.hk/en/pdf/An\%20Anatomy\%20of\%20the\%20World\%20Trade\%20 Network\%20\%28July\%202013\%29.pdf. Aaccessed 10 September 2018.

Clauset A (2011) Power-Law Distributions. Inference, Models and Simulation for Complex Systems Lectures.

Csermely P, London A, Wu LY, Uzzi B (2013) Structure and dynamics of core/periphery networks. Journal of Complex Networks. https://doi.org/10.1093/comnet/cnt016.

De Benedictis, Nenci S, Santoni G, Tajoli L, Vicarelli C (2013) Network Analysis of World Trade using the BACI-CEPII dataset. CEPII, Document de Travail. No.24.

Decarlo LT (1997) On the Meaning and the Use of Kurtosis. Psychological Methods. 2 (3), 292-307.

Deguchi T, Takahashi K, Takayasu H, Takayasu M (2014) Hubs and Authorities in the World Trade Network Using a Weighted HITs Algorithm. PLOSONE https://doi.org/10.1371/journal.pone.0100338.

Du R, Dong G, Tian L, Wang Y, Liu Y, Wang M, Fang G (2016) A Complex Network Perspective on Features and Evolution of World Crude Oil Trade. Energy Procedia https://doi.org/10.1016/j.egypro.2016.12.038.

Duenas, Marco, Giorgio Fagiolo. "Modeling the International-Trade Network: A Gravity Approach". http://arxiv.org/pdf/1112.2867.pdf [11.01.2019]. (2011): 1-29.

Fagiolo G, Squartini T, Garlaschelli D (2013) Null Models of Economic Networks: The Case of the World Trade Web. Journal of Economic Interaction and Coordination

https://doi.org/10.1007/s11403-012-0104-7. 
Fagiolo G, Reyes J, Schiavo S (2010) The Evolution of the World Trade Web: A Weighted-Network Analysis. Journal of Evolutionary Economics https://doi.org/10.1007/s00191-009-0160-x.

Geng JB, Ji Q, Fan Y (2014) A Dynamic Analysis on Global Natural Gas Trade Network. Applied Energy https://doi.org/10.1016/j.apenergy.2014.06.064.

Howell, AJ (2012) Network statistics and modeling the global trade economy: exponential random graph models and latent space models: is geography dead?. Dissertation, University of California

Jin T, Kim J (2018) Coal Consumption and Economic Growth: Panel Cointegration and Causality Evidence from OECD and Non-OECD Countries. Sustainability DOI: 10.3390/su10030660.

Kleinberg JM (1999) Authoritative Sources in a Hyperlinked Environment. Journal of the ACM DOI: $10.1145 / 324133.324140$

König DM, Battiston S (2009) From graph theory to models of economic networks: a tutorial. In: Naimzada AK et al. (ed) Networks, Topology and Dynamics, Springer-Verlag Berlin Heidelberg, 23-63. https://doi.org/10.1007/978-3-540-68409-1_2.

Leon RC, Machado C, Sarmiento Paipilla M (2015) Identifying Central Bank Liquidity SuperSpreaders in Interbank Funds Networks. EBC Discussion Paper, 2015-010.

Li J, Li Z (2011) A Causlaity Analysis of Coal Consumption and Economic Growth for China and India. Natural Resources DOI: 10.4236/nr.2011.21007.

Newman MEJ (2010) Networks An Introduction. 1st pr. Oxford University Press.

Newman, M.E.J. "The Structure and Function of Complex Networks". http://arxiv.org/pdf/condmat/0303516.pdf [11.01.2019]: 1-58.

Reichardt J (2009) Introduction to Complex Networks. In: Structure in Complex Networks Lecture Notes in Physics, No: 766. Springer-Verlag Berlin Heidelberg, pp. 1-11.

Serrano A, Boguna M (2006) Clustering in Complex Networks: General Formalism. Physical Review DOI: $\quad$ 10.1103/PhysRevE.74.056114.

Shahbaz M, Dube S (2012) Reisiting the Relationship Between Coal Consumption and Economic Growth: Cointegration and Causality Analysis in Pakistan. Applied Econometrics and International Deelopment. 12-1, pp.165-192.

Tesfatsion, Leigh. "Agent-based Computational Economics: A Constructive Approach to Economic Theory". Handbook of Computational Economics c.2. eds. K. Judd, L. Tesfatsion. NorthHolland: ELSEIVER, 2006: 831-880.

Von Hippel P (2010) Skewness. In: Lovric M (ed) International Encyclopedia of Statistical Science. Springer, New York https://lbj.utexas.edu/sites/default/files/file/news/Skew.pdf Accessed 10 September 2018.

Wang XF, Chen G (2003) Complex Networks: Small-World, Scale-Free and Beyond. IEEE Circuits and Systems Magazine DOI: 10.1109/MCAS.2003.1228503.

Wei W, Liu G (2012) Bringing Order to the World Trade Network. 2012 International Conference on Economics Marketing and Management, IPEDR, 28, pp. 88-92.

Xiaoqing $\mathrm{H}$, An $\mathrm{H}$, Hai Q (2014) Evolution of fossil energy international trade pattern based on complex network. Energy Procedia https://doi.org/10.1016/j.egypro.2014.11.1152.

Xu H, Qin J (2015) The Structure and Nodes' Role of the World Coal Trade Network. Journal of Chinese Economic and Business Studies https://doi.org/10.1080/14765284.2014.994848.

Zhang Z, Lan H, Xing W (2018) Global Trade Pattern of Crude Oil and Petroleum Products: Analysis Based on Complex Network. IOP Conference Series: Earth and Environmental Science, 153.

Zhong W, An H, Gao X, Sun X (2014) The evolution of communities in the international oil trade network. Physica A. https://doi.org/10.1016/j.physa.2014.06.055.

Zhong W, An H (2014) The role of China in the international crude oil trade network. Energy Procedia https://doi.org/10.1016/j.egypro.2014.12.030. 
Zhong W, An H, Shen L, Fang W, Gao X, Dong D (2017) The Roles of Countries in the International Fossil Fuel Trade: An Emergy and Network Analysis. Energy Policy. https://doi.org/10.1016/j.enpol.2016.07.025.

*** (2015) China Coal Consumption Cap Plan and Research Report: Recommendations for $13^{\text {th }}$ Five-Year Plan. https://d2ouvy59p0dg6k.cloudfront.net/downloads/china_coal_consumption_cap_plan_and_r esearch_report_recommendations_for_the_13fyp.pdf Accessed 9 September 2018. 